\title{
An Experimental Study on Seismic Damage Indicator Considering CAV Concept
}

\author{
Lee, Jong-Rim ${ }^{1)}$ and Lee, Sang-Hoon ${ }^{2)}$
}

1) Civil/Architectural Eng. Group, Korea Electric Power Research Institute, KEPCO

2) Power Engineering Research Institute, Korea Power Engineering Co., Inc.

\begin{abstract}
The nuclear power plant (NPP) should be shut down for inspection and tests prior to a return to power if the earthquake exceeds the operating basis earthquake (OBE). The OBE at the plant is considered to have been exceeded if the computed cumulative absolute velocity (CAV) from the earthquake record is greater than $0.16 \mathrm{~g}$-sec. However, the CAV criterion should be determined considering the seismic and structural characteristics of the plant. An experimental study using shaking table is conducted in this study to evaluate intensity of CAV criterion. Appropriate level of CAV is evaluated based on the test results using the developed seismic damage indicator (SDI) model. The model consists of stacked acrylic cylinders and is developed to behave consistently for each directional seismic load. The result of this study indicates that the CAV criterion of 0.16g.sec is conservative enough to be applied to Korean NPPs since the CAV value of the seismic input motion of the Korean standard NPPs ranges from 0.3 to $0.5 \mathrm{~g}$-sec. The developed SDI is expected to be useful not only in easily determining $\mathrm{OBE}$ exceedance but also in evaluating earthquake damage quantitatively to provide guidelines for better post-shutdown inspection and test.
\end{abstract}

\section{INTRODUCTION}

Since several earthquake observatory stations have been constructed at outskirts of the NPP in June 2, 1999, an earthquake event (See Table 1) was measured at WSC station located at one of electric substation, which exceeded OBE of $0.1 \mathrm{~g}$-sec at $10 \mathrm{~Hz}$ (See Fig.1 and Fig. 2). However, no damage has been found in the facility. Generally, following an earthquake exceeding OBE, operator performs the first assessment of the plant's condition immediately, and shut down the plant. A return to power is possible after plant shows that no potential damage resulted from the earthquake[1]. In Korean peninsula, it is highly probable that small, such a nondamaging earthquakes, which have low energy with high frequency components, may occur often in the future. Similar situations happened in the U.S., and the plants should have shut down, and shown that no significant damage resulted to the plant through extensive analyses. Therefore, to avoid unnecessary plant shutdown due to small nondamaging earthquakes, it is required to set up an analytical criterion for determining when an OBE is exceeded. EPRI defined the OBE exceedance as the one causing potential damage to the well-designed structure as well as the exceedance of $\mathrm{OBE}$ design spectrum and concluded that $\mathrm{CAV}$ is the best single parameter for determining the damage threshold of earthquakes[2].

\section{BACKGROUND OF CAV}

The original CAV is defined as equation (1). This parameter is the area under the absolute acceleration and is primarily sensitive to potentially damaging low-frequency motions, but less sensitive to high-frequency motions which are nondamaging. 
Table 1. Peak ground accelerations of Kyungju earthquake (June 2, 1999)

\begin{tabular}{|c|c|c|c|c|}
\hline \multirow{2}{*}{ Station ID } & \multirow{2}{*}{$\begin{array}{c}\text { Epicentral Distance } \\
(\mathrm{km})\end{array}$} & \multicolumn{3}{|c|}{ Peak Ground Acceleration $(\mathrm{g})$} \\
\cline { 3 - 5 } & & $\mathrm{E}-\mathrm{W}$ & $\mathrm{N}-\mathrm{S}$ & U-D \\
\hline WSC & 8.4 & 0.1153 & 0.0900 & 0.0403 \\
\hline
\end{tabular}

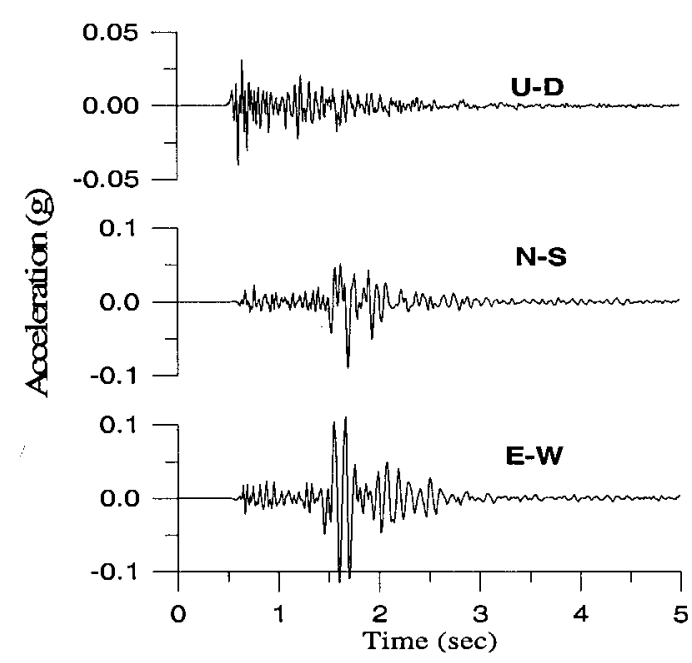

Fig. 1 Acceleration seismograms of Kyungju earthquake at WSC station

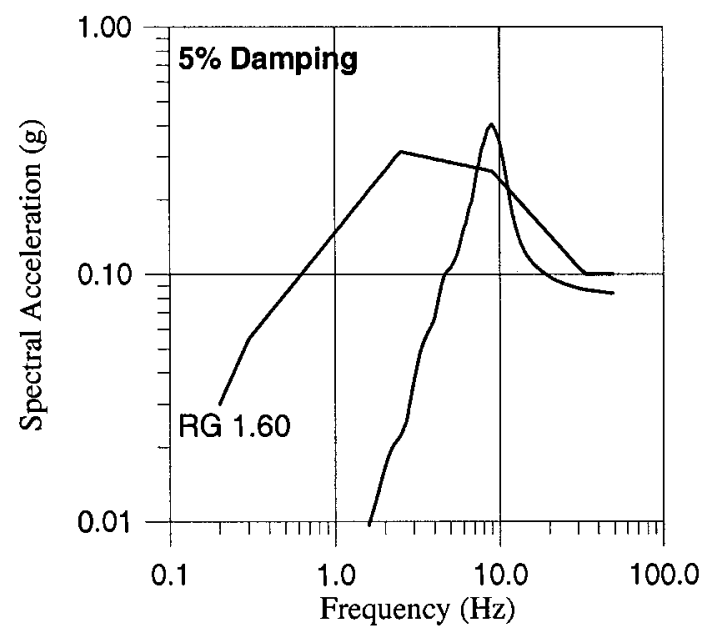

Fig. 2 Comparison of the ground response spectrum with NRC Reg. Guide 1.60 design spectrum

$$
\mathrm{CAV}=\int_{0}^{\mathrm{t}_{\max }}|\mathrm{a}(\mathrm{t})| \mathrm{dt}
$$

where, $a(t)=$ acceleration time history, $t_{\max }=$ duration of record

The CAV was originally defined as equation (1). However, the calculation of CAV over the entire length of the time history can produce values that are significantly affected by low nondamaging acceleration(typically less than $0.025 \mathrm{~g}$ ). Then, CAV defined in equation (1) is revised to incrementally calculate CAV in one second intervals as follows[3].

$$
\mathrm{CAV}_{\text {TOTAL }}=\mathrm{CAV}_{\mathrm{i}}+\int_{\mathrm{t}_{\mathrm{i}-1}}^{\mathrm{t}_{\mathrm{i}}}|\mathrm{a}(\mathrm{t})| \mathrm{dt}
$$

where, $a(t)=$ acceleration value in a one-second interval where at least one value exceeds $0.025 \mathrm{~g}$, and $\mathrm{i}=1, \mathrm{n}$ with $\mathrm{n}$ equal to the record length in seconds.

Using equation (2) CAV can be applied for determination of OBE exceedance criteria, and the procedure is illustrated as follows[4].

\section{1) Response Spectrum Check}

The OBE response spectrum is exceeded if any one of the three components (two horizontal and one vertical) of the 5 percent of critical damping response spectra generated using free-field ground motion is larger than the OBE design response spectral acceleration or $0.2 \mathrm{~g}$, whichever is greater, for frequencies between 2 to $10 \mathrm{~Hz}$, or the OBE design response spectral velocity or a spectral velocity of 6 inches per second, whichever is greater, for frequencies between 1 
and $2 \mathrm{~Hz}$.

\section{2) CAV Check}

The CAV check is exceeded if any CAV calculated according to equation (2) is greater than $0.16 \mathrm{~g}$-second

The CAV value to the earthquake ground motion of the Fig. 1 indicates $0.04 \mathrm{~g}$-sec as shown in Fig. 3. Therefore, the earthquake motion did not exceed the $\mathrm{OBE}$ since the calculated CAV value is smaller than the criteria.

\section{SEISMIC DAMAGE INDICATOR}

Although EPRI has set up the CAV value of $0.16 \mathrm{~g}$-sec as the applicable level for NPP structures, CAV value may be affected by some factors, such as the seismological condition of the plant site and structural condition of the plant[5]. To check OBE exceedance for felt earthquakes, it is necessary in advance to acquire and analyze the earthquake using seismic instruments. Mostly, seismic monitoring system of the NPP is the only way that the operator can get a signal indicating seismic information for an earthquake. If a supplementary model responding at a critical earthquake level is available in the NPP, it will be helpful for operator to evaluate the earthquake damage easily. In the event that no damage is found in the safety-related equipment and structures during the focused post-shutdown inspections, but damage is found in the nonsafety-related earthquake damage indicators, then the following course of action is recommended by EPRI. That is, if the level of observed damage based on the post-

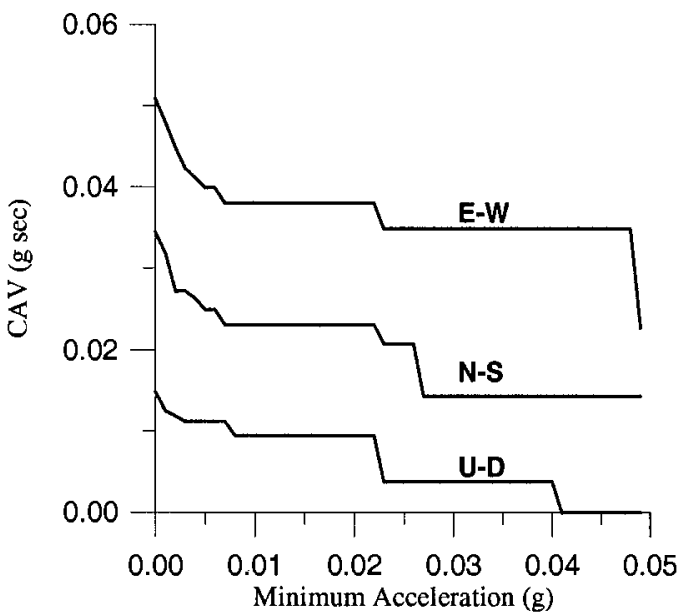

Fig. 3 CAV for Kyungju earthquake at WSC station
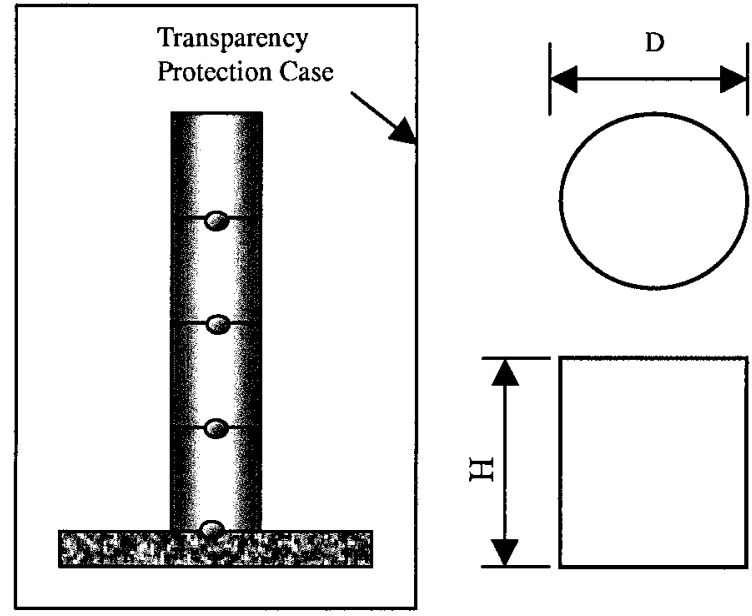

Fig. 4 The developed model of Seismic Damage Indicator (SDI) shutdown inspections corresponds to intensity 0 based on the EPRI damage scale for NPPs, then additional inspections of safety-related equipment and structures are not considered to be warranted. EPRI recommend several SDI such as switchyard equipment, suspended ceilings, unanchored cabinet and storage racks etc. for focused inspection.

In this study, an attempt is made to develop a SDI quantitatively evaluated, because it may be helpful to provide guidelines for better post-shutdown inspection and test. A combination of cylindrical blocks having simple geometry is selected to guarantee consistent damage behavior of SDI to the input ground motion. Cylindrical blocks are combined with the small blocks of the constant height (See Fig. 4). The model should react consistently to any direction for horizontal excitation and be not only semi-permanent but also easy to built-up, disassemble and change the height. However, because stacked blocks fall down so easily during shaking table test, a bearing ball of $4.75 \mathrm{~mm}(3 / 16 \mathrm{inch})$ is to be placed at the center of cylindrical block section as a partial shear key to prevent sliding collapse by small excitation. The best adequate height of the stacked blocks showing the collapse is derived from iterative experiments. Table 2 describes the detailed specifications of the cylindrical blocks. 
Table 2. Requirements for the SDI test model

\begin{tabular}{|c|c|l|}
\hline Item & Spec. & \multicolumn{1}{|c|}{ Comment } \\
\hline H/D & $\begin{array}{c}0.5,1.0, \\
1.5,2.0\end{array}$ & $\begin{array}{l}\text { Diameter }(\mathrm{D})=10 \mathrm{~cm} \\
\text { Height }(\mathrm{H})=5,10,15,20 \mathrm{~cm}\end{array}$ \\
\hline $\begin{array}{c}\text { Total } \\
\text { Height }\end{array}$ & - & $\begin{array}{l}\text { It needs the adequate height to respond to the design earthquake, but it was } \\
\text { intended that the total height of SDI shall not higher than the one of operator }\end{array}$ \\
\hline Material & Acrylic & $\begin{array}{l}\text { Corrosion resistant, availability to reuse, the adequate unit weight for } \\
\text { considering inertia force of earthquake, durability }\end{array}$ \\
\hline Base plate & Acrylic & $\begin{array}{l}\text { Solidly made to support weight of SDI and fixed to shaking table (desirable } \\
\text { weight is two times larger than that of SDI) }\end{array}$ \\
\hline
\end{tabular}

\section{INPUT EXCITATION}

Since it is so difficult to use the real earthquake ground motions satisfying this experimental condition, some artificial time histories were generated[5]. An artificial time history can be constructed on the basis that any periodic function can be expanded into a series of sinusoidal functions as equation (3).

$$
\ddot{Z}(t)=\sum_{i=1}^{n} A_{i} \sin \left(\omega_{i} t+\phi_{i}\right)
$$

$A_{i}$ is the amplitude and $\phi_{i}$ is the phase angle of the $i$ times contributing sinusoid.

In order to modify artificial time history consistent with the required design response spectrum using equation (3), response error calculated at the given control frequency point as equation (4) is added sequentially to the artificial time history.

$$
\delta \mathrm{R}^{\max }\left(\omega_{\mathrm{i}}, \xi_{\mathrm{k}}\right)=\int_{0}^{\mathrm{t}_{\mathrm{mi}}} \delta \ddot{Z}(\tau) \mathrm{h}_{\mathrm{ik}}\left(\mathrm{t}_{\mathrm{mi}}-\tau\right) \mathrm{d} \tau
$$

$t_{m i}$ is the time at which the maximum spectral response occurs, $h_{i k}(t)$ is the unit impulse response function to the damping $\xi_{\mathrm{k}}$ and the frequency $\omega_{\mathrm{i}}$, and can be defined as equation (5).

$$
h(t)=-\frac{1}{\omega_{d i}} \exp \left(-\omega_{i} \xi_{k} t\right) \sin \omega_{d i} t
$$

Two artificial time histories are generated for input excitations. One is for Type A giving a CAV value of $0.16 \mathrm{~g}$-sec and another for Type B satisfying standard design ground response spectra of U.S. NRC Reg. Guide 1.60. The CAV values of design ground motions for the Korean standard NPPs resulted in $0.5 \mathrm{~g}$-sec for horizontal components, and $0.3 \mathrm{~g}$-sec for vertical component as shown in Fig. 5. Therefore, it can be assumed that the model satisfying input excitation for the type B may respond to the CAV value of $0.3 \mathrm{~g}$-sec. Type A meets the $\mathrm{OBE}$ exceedance criteria, but does not satisfy OBE design criteria. Type B satisfies not only the OBE exceedance criteria, but also OBE design criteria. These input ground motions are also modified to represent the same input excitation as the amplification at the floor level, which the model is to be installed. 


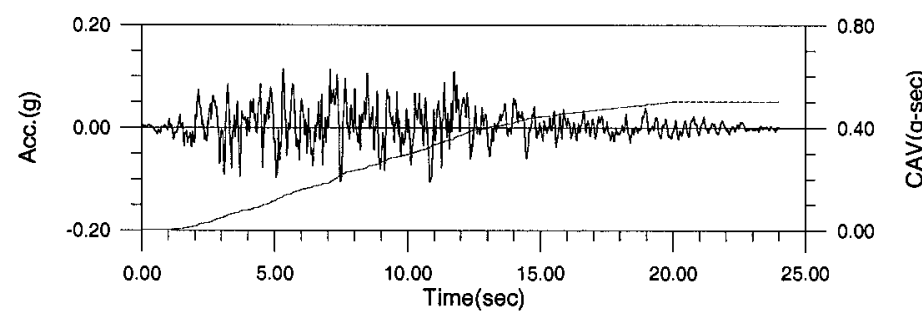

(a) North-South direction

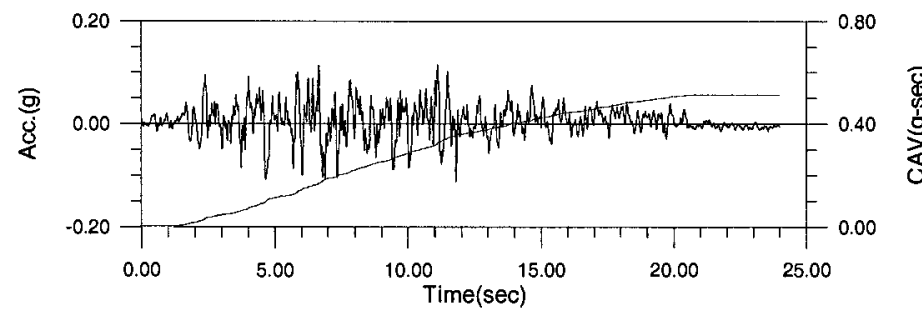

(b) East-West direction

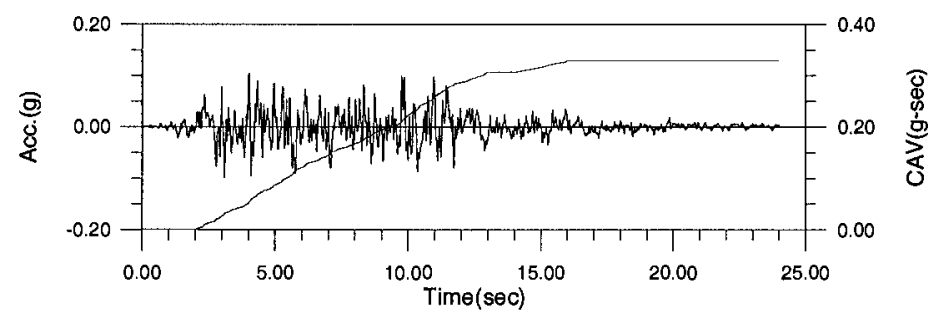

(b) Vertical direction

Fig. 5 CAV plots of seismic input motion for Korean standard NPP

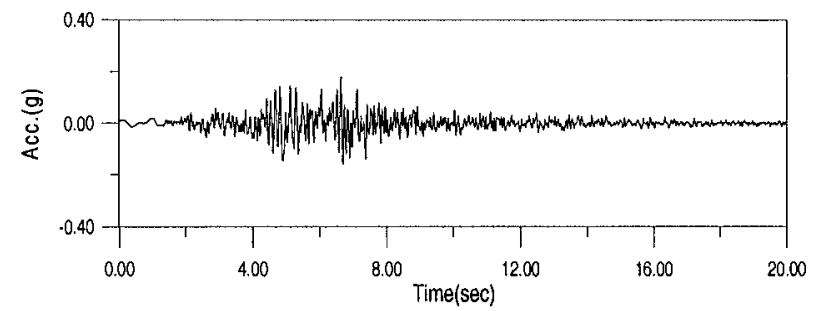

(a) NS direction

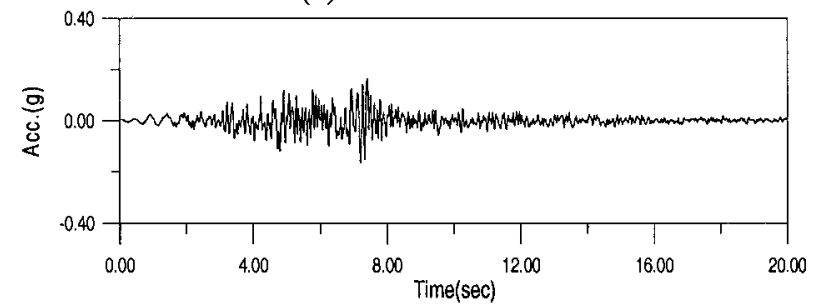

(b) EW direction

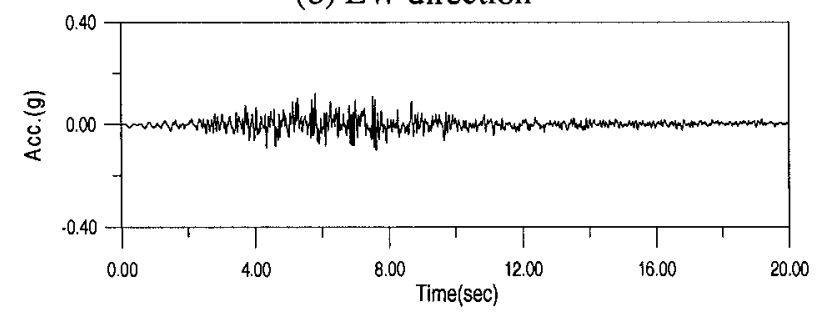

(c) VT direction

Fig.6 Input excitation corresponding to type A
The generated acceleration time history and its response spectrum of 5\% damping for input excitation of type A are plotted in Fig. 6 and Fig. 8 respectively. The duration of the time history generated is 20 seconds, and time increment is set up as 0.005 seconds. The maximum peak ground acceleration for each component reached $0.179 \mathrm{~g}, 0.165 \mathrm{~g}$, and $0.120 \mathrm{~g}$. The acceleration time history generated and its response spectrum of $5 \%$ damping for input excitation of type $B$ are shown in Fig. 7 and Fig 9 respectively. The duration of the time history generated is 24 seconds, and time increment are the same as type A. The maximum peak ground acceleration for each component reached $0.316 \mathrm{~g}, 0.329 \mathrm{~g}$, and $0.229 \mathrm{~g}$.

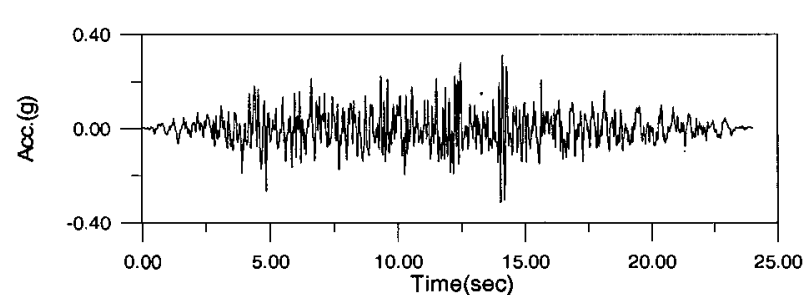

(a) NS direction

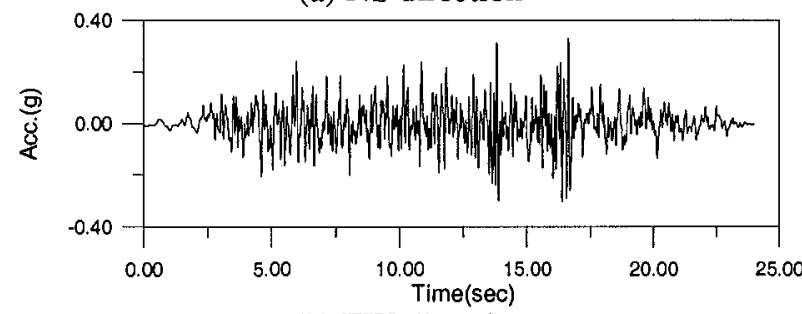

(b) EW direction

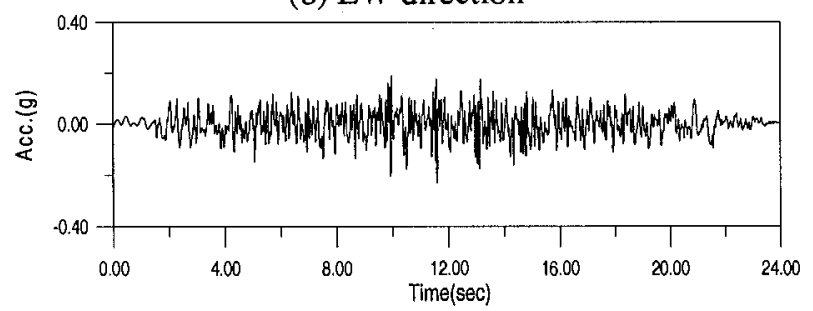

(c) VT direction

Fig.7 Input excitation corresponding to type B 


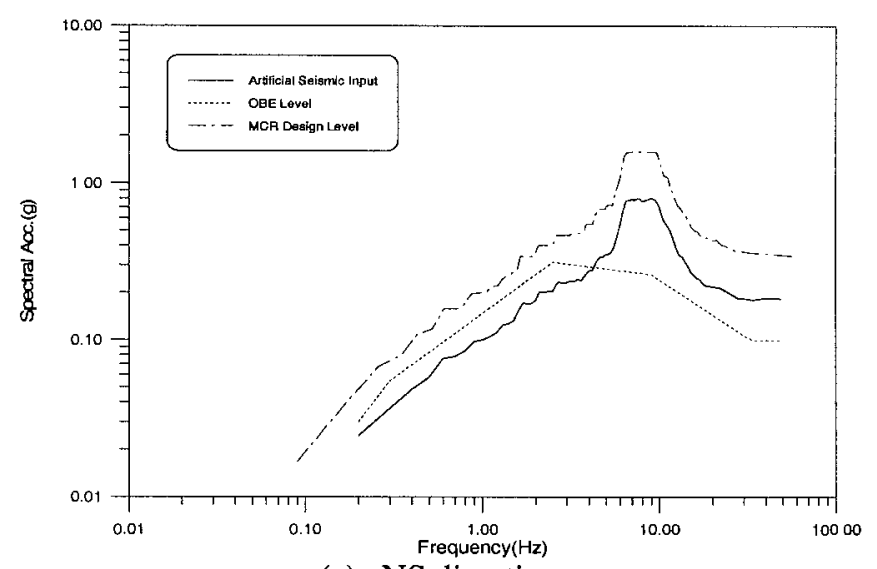

(a) NS direction

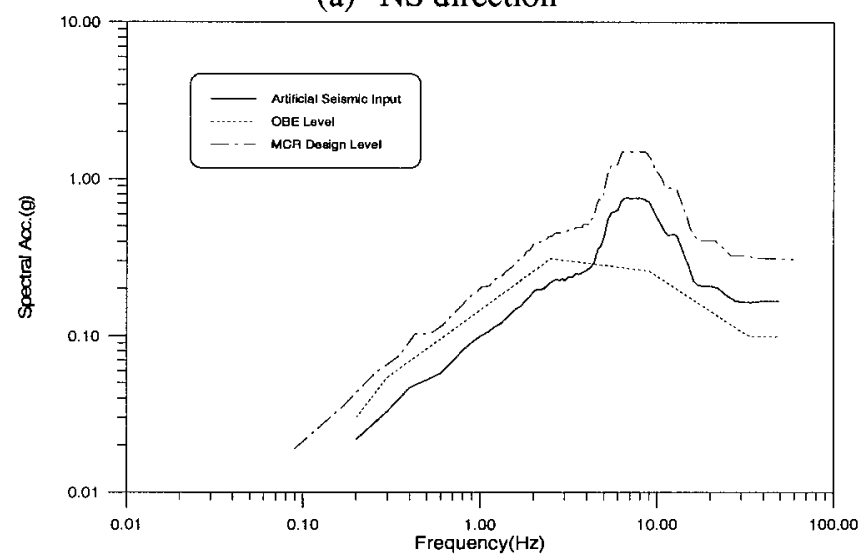

(b) EW direction

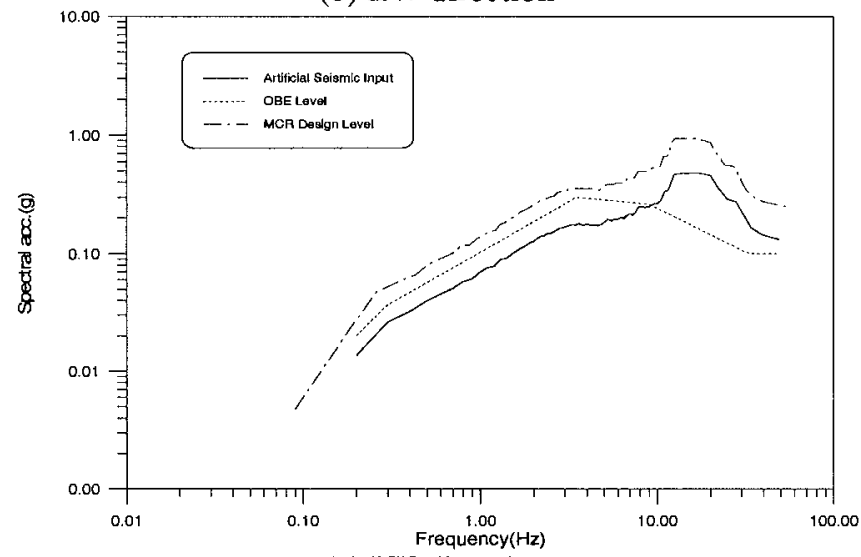

(c) VT direction

Fig. 8 Comparison of response spectrum of type A motion (OBE Level: design ground response spectrum, MCR Design Level: floor response spectrum at MCR floor)

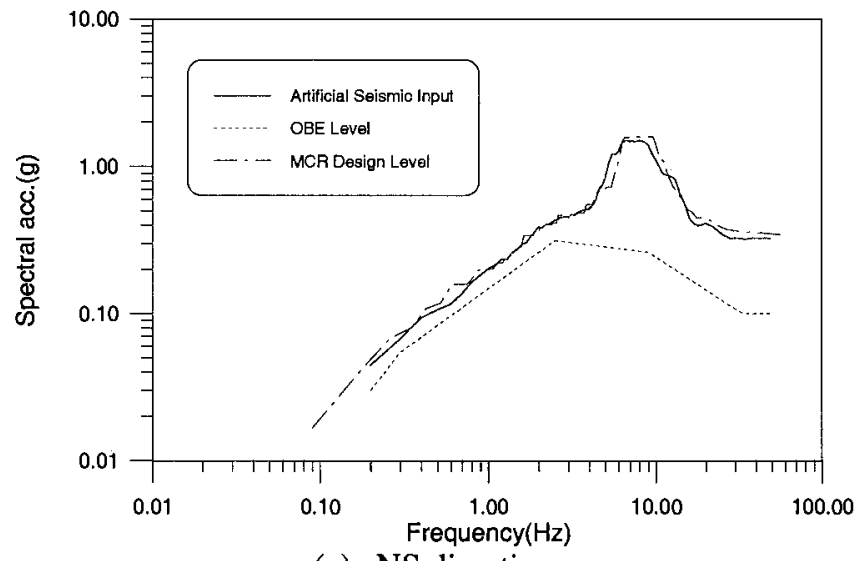

(a) NS direction

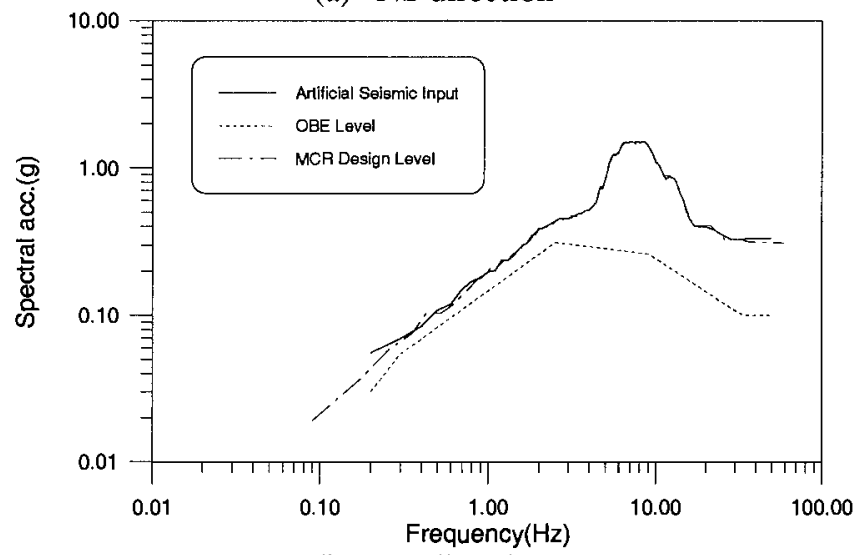

(b) EW direction

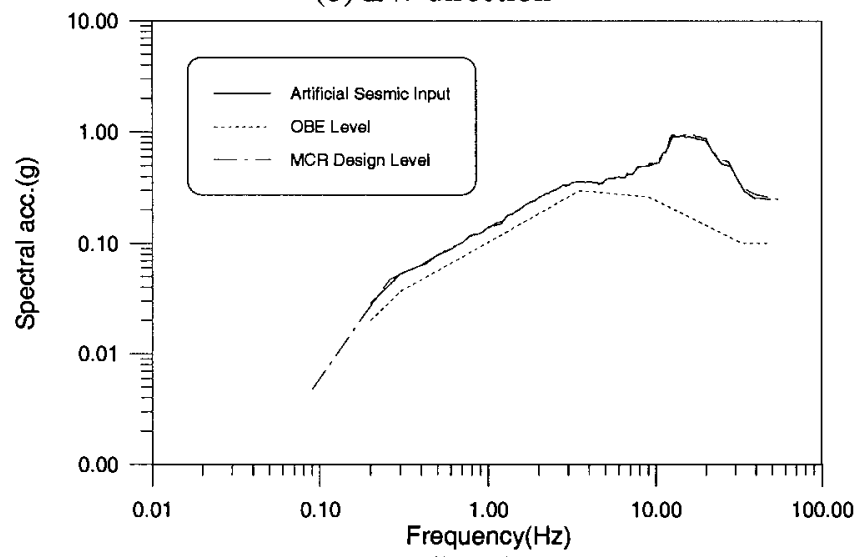

(c) VT direction

Fig. 9 Comparison of response spectrum of type B motion (OBE Level: design ground response spectrum, MCR Design Level: floor response spectrum at MCR floor) 


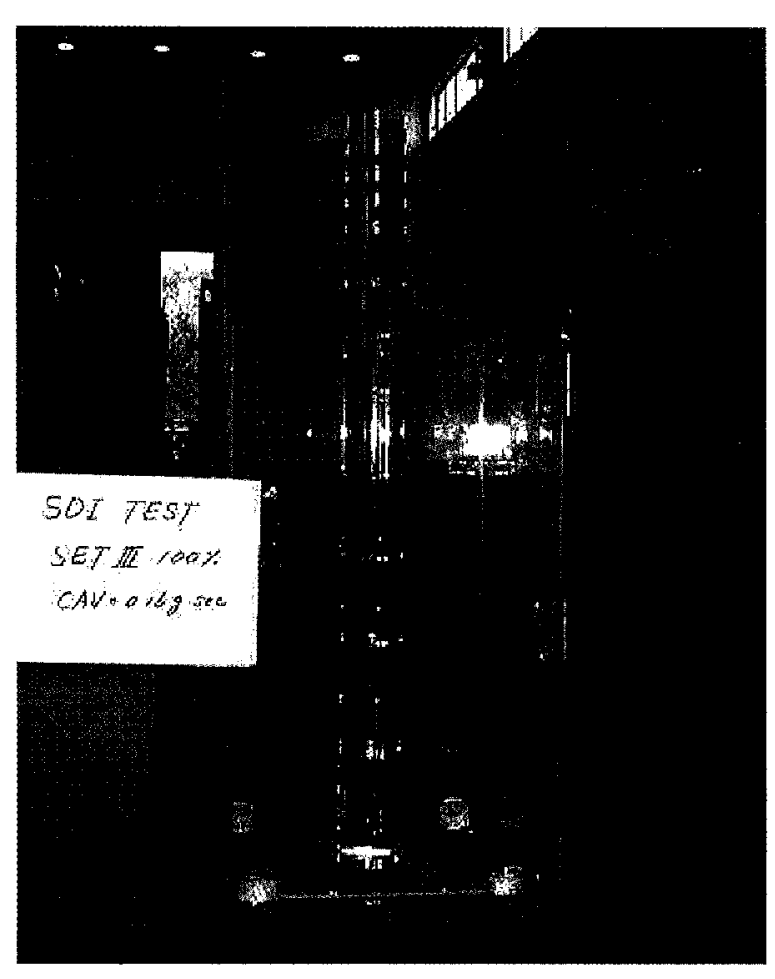

Fig .10 The optimum combination for type A

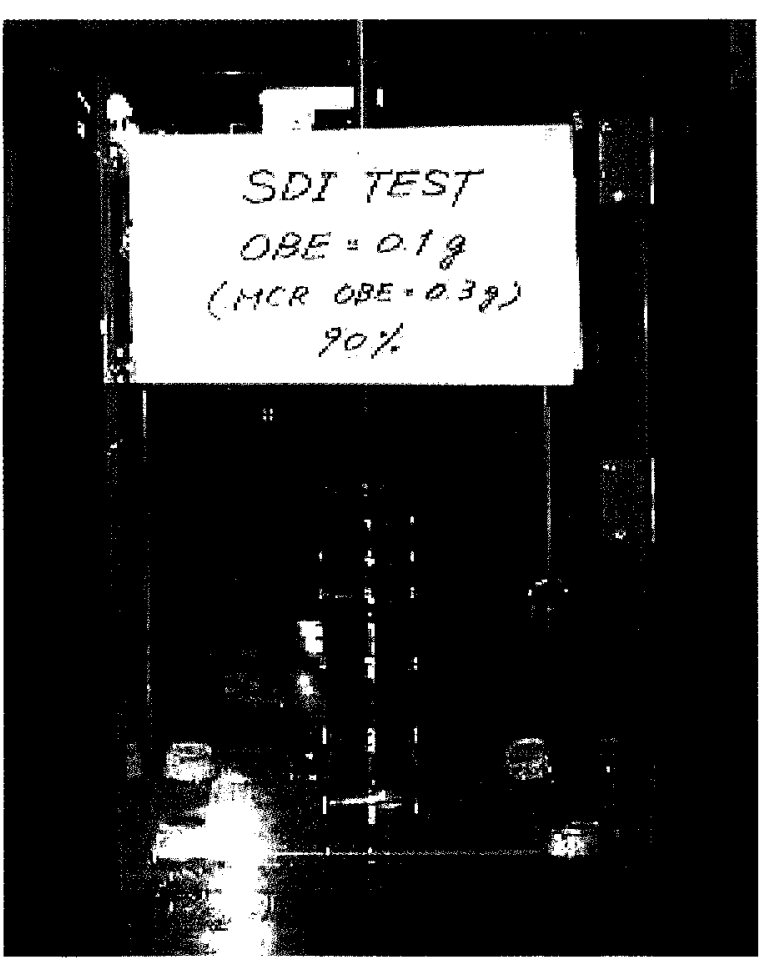

Fig.11 The optimum combination for type B

\section{TEST RESULTS}

Fig. 10 and Fig. 11 show the SDI test models installed at 6-DOF shaking table of Korea Institute of Machinery \& Materials. The shaking table can simulate 3 directional input motion simultaneously for the test. Two sets of SDI test model are prepared for the test.

First, the input excitation corresponding to type $\mathrm{A}$ is applied to the test models, and the overturning of the model is checked with stacked height. The amplitude of input motion is also increased step by step changing the stacked height of the models. Through the iterative experiments, the test model shows no collapse at $90 \%$ level of excitation and all collapse at $100 \%$ level of excitation all the time. And, the adequate height and optimum combination of block is also selected for the input excitation corresponding to type $\mathrm{B}$.

The test result indicates that the selected optimum combination for type A consists of $20 \mathrm{~cm} \times 2+15 \mathrm{~cm} \times 2+10 \mathrm{~cm} \times$ $3+5 \mathrm{~cm} \times 4$ (The total height is $120 \mathrm{~cm}$ from the bottom) as shown in Fig. 10. For type B, the combination consists of $10 \mathrm{~cm}$ $\times 3+5 \mathrm{~cm} \times 3$ (The total height is $45 \mathrm{~cm}$ from the bottom) as shown in Fig. 11 .

\section{CONCLUSIONS}

In this study, an attempt is made to develop a SDI quantitatively evaluated for guidelines for better post-shutdown inspection and test. The newly developed SDI models are tested independently for the two seismic load conditions, an artificial seismic load exceeding only the CAV criteria $(0.16 \mathrm{~g}-\mathrm{sec})$ of U.S. NRC Reg. Guide 1.166 and a seismic input motion set meeting the OBE design criteria of U.S. NRC Reg. Guide 1.60. The result of this study indicates that the CAV criterion of $0.16 \mathrm{~g} . \mathrm{sec}$ is conservative enough to be applied to Korean NPPs since the CAV value of the seismic input motion 
of the Korean standard NPPs ranges from 0.3 to $0.5 \mathrm{~g}$-sec. By applying CAV criterion it is expected to avoid unnecessary plant shutdown due to small, nondamaging earthquake. The SDI models developed in this study are expected to be useful not only in easily determining OBE exceedance and but also in evaluating earthquake damage quantitatively for providing guidelines for better post-shutdown inspection and test. .

\section{REFERENCES}

1. EPRI NP-6695, Guidelines for Nuclear Plant Response to an Earthquake, Palo Alto, California: Electric Power Research Institute, prepared by MPR Associates, Inc., December 1989.

2. EPRI NP-5930, A Criterion for Determining Exceedance of the Operating Basis Earthquake, Palo Alto, California: Electric Power Research Institute, prepared by Jack R. Benjamin and Associates, Inc., July 1988.

3. EPRI TR-100082, Standardization of the Cumulative Absolute Velocity, Palo Alto, California: Electric Power Research Institute, prepared by Yankee Atomic Electric Company, December 1991.

4. Technical Report, Development of Post-Earthquake Guidelines and Evaluation Methodology for Nuclear Power Plant, Korea Electric Power Research Institute, 1999.

5. Technical Report, An Enhanced Approach to Generate Artificial Earthquake Time History for Multiple-Damping Design Response Spectra, Korea Power Engineering Co. Inc., 1996. 